\title{
Report
}

\section{Attitudes towards euthanasia and assisted suicide among Sudanese doctors}

\author{
A.M. Ahmed, ${ }^{1}$ M.M. Kheir, ${ }^{2}$ A. Abdel Rahman, ${ }^{3}$ N.H. Ahmed ${ }^{4}$ and M.E. Abdalla ${ }^{5}$
}

SUMMAFY An anonymous questlonnalre was used to survey the attitudes of 382 doctors towards euthanasia and assisted suicide at Khartoum's two main hospitals. Of the 382,248 responded $(65 \%$ response rate). The mean age was $38 \pm 13.5$ years; male:female ratio was $130: 118 ; 66 \%$ were house staff, $34 \%$ specialists; 02\% Muslim, $8 \%$ Christian. The vast majority $(85 \%)$ strongly opposed the practices, while $15 \%$ thought they should be performed only in certain situations, subject to strict safeguards. Reasons given for opposition included religious beliefs, inconsistency with the doctor's role, presence of subtle pressures on patients, and potential for misuse among the physically and intellectually handicapped.

\section{Introduction}

At the dawn of the third millennium the world is increasingly a single village. Everywhere, traditional and more recent cultural values are being challenged. The moral and ethical issues surrounding medical termination of life have been openly and extensively discussed over the past 20 years. As medicine has increasingly enabled the chronically ill to live longer lives of dubious quality, euthanasia has become a more actively debated issue. Although euthanasia and assisted suicide are illegal in most countries, they are legal in the Netherlands and the state of Oregon in the United States of America [ 1,2$]$. In Australia's Northern Territory, provincial legislation initially enabling euthanasia was almost immediately overridden by that country's fed- eral parliament. By contrast, in the Netherlands the practices have gained a degree of social and professional acceptance, and the medical community has developed standard medical and ethical criteria that must be met for euthanasia to be considered [ 1$]$. In Sudan, euthanasia and assisted suicide are illegal. Neither the lay community nor the medical profession has been exposed to the international debate on these issues.

In this, the first survey of its kind in Sudan, we sought to determine the attitudes of junior and senior Sudanese doctors to euthanasia and assisted suicide. In carrying out the survey, we were less concerned to promote a particular view for or against euthanasia than to contribute to the worldwide debate.

'Department of Medicine, University of Bahr Elghazal, Khartoum, Sudan.

2Department of Medicine; 'Department of Psychiatry, University of Khartoum, Khartoum, Sudan.

${ }^{4}$ College of Technological Sciences, Omdurman, Sudan.

${ }^{5}$ Police Central Hospital, Khartoum, Sudan.

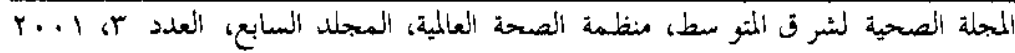




\section{Methods}

We selected potential respondents from the two main hospitals in Khartoum, Sudan Khartoum Teaching Hospital (KTII) and Omdurman Teaching Hospital (OTH). KTH is a 750-bed hospital with 298 house and resident staff and 84 specialists. OTH is a 600-bed facility with 193 house and resident staff and 37 specialists. We distributed an anonymous questionnaire to all doctors available on a given day in April, 2000.

The questionnaire consisted of questions about the characteristics of respondents, their attitudes to assisted suicide and euthanasia, their opinion on legalization, their willingness to participate in these practices, and the safeguards or restrictions needed if the practices were legalized. Respondents were required to give a rating according to a three-point scale indicating degree of agreement (agree, neutral or disagree). To obviate any uncertainty, the questionnaire clearly defined euthanasia as "the deliberate administration of an overdose of medication to an ill patent at their request with a primary intent to end their life" [3]. Assisted suicide was defined as "prescribing a mucdication (e.g. narcotics), or counselling an ill patient to be able to use an overdose to end their life" [3]. Copies of the questionaaire are available, on request, from the principal author.

\section{Results}

Of 382 doctors to whom the questionnaire was distributed, 248 (65\%) completed the questionnaire. The characteristics of the respondents are shown in Table 1 . The majority $(72 \%)$ were graduates of Sudanese universities; the remainder were graduates of different Arab and Eastern European medical schools. The majority of the $92 \%$ of respondents who said they were Muslim

\begin{tabular}{|c|c|c|}
\hline Characteristics of respondents & No. & $\%$ \\
\hline \multicolumn{3}{|l|}{ Sex } \\
\hline $\begin{array}{l}\text { Male } \\
\text { Female }\end{array}$ & $\begin{array}{l}130 \\
118\end{array}$ & $\begin{array}{l}52 \\
48\end{array}$ \\
\hline \multicolumn{3}{|l|}{ Religion } \\
\hline $\begin{array}{l}\text { Mustim } \\
\text { Christian }\end{array}$ & $\begin{array}{r}228 \\
20\end{array}$ & $\begin{array}{r}92 \\
8\end{array}$ \\
\hline \multicolumn{3}{|l|}{ Duties } \\
\hline $\begin{array}{l}\text { House staff } \\
\text { Specialist staff }\end{array}$ & $\begin{array}{r}164 \\
84\end{array}$ & $\begin{array}{l}66 \\
34\end{array}$ \\
\hline \multicolumn{3}{|l|}{ Familiarity with subjecta } \\
\hline $\begin{array}{l}\text { Familiar } \\
\text { Unfamiliar }\end{array}$ & $\begin{array}{r}223 \\
25\end{array}$ & $\begin{array}{l}90 \\
10\end{array}$ \\
\hline
\end{tabular}

Specifically, familiarity with the terms euthanasia and assisted swigide.

The mean age of respondents was $38 \pm 13.5$ years.

The mean number of terminally-ill patients seen by oach dootor in the previous month was $5 \pm 11$ patients.

indicated that they adhered moderately to Islamic teaching. Although a large majority $(85 \%)$ stated unequivocally that euthanasia and assisted suicide were never ethically justified, $15 \%$ believed the practices could be justified in some situations. None of the respondents stated that they would be willing to perform euthanasia themselves.

Of those allowing for the possibility of euthanasia and assisted suicide in certain situations, all were male, graduates of foreign schools and self-described as being moderately religious. Only $8 \%$ of respondents stated that any of their terminally-ill patients (especially those suffering severe pain) had expressed ideas of suicide; of the patients that had, none had asked their doctors to terminate their lives. 
The reasons given by respondents for their opposition to legalizing euthanasia and assisted suicide are shown in Table 2 . Those in favour suggested the following restrictions and safe-guards:

- psychiatric consultation

- availability of alternatives such as hospice care

- treatment of depression

- two or more supporting doctors' opinions

- consent of the family, and

- a committee nominated by the Medical Council to review and agree to the decision.

\section{Discussion}

The unexpectedly high response rate in our survey $(65 \%)$ comnares favourahly with a response rate of $69 \%$ in a similar survey of doctors in Washington State (United States of America) by Cohen et al [3]. However, while $85 \%$ of the Khartoum doctors were strongly opposed to euthanasia and assisted suicide, only $48 \%$ were opposed in the Washington study [3]. Clearly, although Khartoum doctors, like their Washington counterparts, are willing to participate in the current international debate over euthanasia and assisted suicide, major cultural differences between Sudan and the United States of America are suggested by the differing attitudes. It is interesting that only a minority of the proponents of these practices surveyed in the Washington study said that they would be willing to perform euthanasia themselves. Clearly, the relatively short time the subject has been debated and, perhaps more importantly, the Hippocratic oath have not facilitated the cstablishment of these practices in the medical profession.

Over $90 \%$ of the Khartoum dociors who were opposed to the practices cited religious grounds, compared to $56 \%$ in the American study [3]. The Catholic and Lutheran Churches oppose all forms of euthanasia. Islam (the religion of the majority of Sudanese) not only opposes euthanasia, but encourages believers to view pain and suffering as a potential blessing. Muslims

Table 2 Reasons cited by the 248 doctors for their opposition to legalizing euthanasia and assisted suicide, Khartoum and Omdurman Teaching Hospitals, Sudan, April, 2000

\begin{tabular}{ll}
\hline Reason for opposition & $\%$ \\
\hline Religious beliefs & 90 \\
Inconsistent with the doctor's role in life preservation & 85 \\
Fear of not adhoring to prosoribod roquiromonts & 84 \\
Presence of subtle pressure on patients fearing dependency or humiliation & 72 \\
Loss of mental competence may impair a patient's decision & 68 \\
Widespread misuse tor handicapped and retarded patients & 60 \\
May impair scientific research to solve the problems of the dying & 58 \\
\hline
\end{tabular}

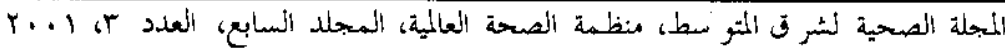


strictly believe that only God should terminate their lives. An Islamic verdict (fatwa) 5 years ago stated it is not a sin for a patient to refuse treatments of unpredictable efficacy [4]. In a study carried out in Saudi Arabia (where there is a strict adherence to Islamic teaching), $58 \%$ of doctors believed patients in intensive care units had the right to refuse treatment if it was futile [5]. This is in keeping with the earliest Islamic attitudes to seeking remedies since the time of the Prophet Muhammad whereby a patient has the right to refuse a remedy, especially if it is futile. Neither the fatwa nor the Saudi doctors' views are indicative of any new trend; neither do they suggest the potential for attitude changes towards euthanasia.

Some opponents of elthanasia in our study argued that because effective palliative therapy is rarely available due to insufficient resources, then if euthanasia were legalized, it would become a substitute for securing efficient palliation. This is supported by the fact that in the Washington study, American oncologists and haematologists, who have the greatest exposure to terminally ill patients, were the strongest opponents of euthanasia and assisted suicide [3]. In the Netherlands, two-thirds of requests for euthanasia or suicide are withdrawn, often as the result of palliative intervention [2].

Despite the wide dehate over euthanasia and assisted suicide, there has been little discussion of the actual clinical outcome of these procedures [6]. Complications arising from doctor-assisted suicide or euthanasia add to the existing suffering of the patient. Groenewoud et al. reported that complications were more likely with doctor-assisted suicide than with euthanasia [I]. The study reported that the attending doctor had been required to intervene by administering a lethal drug in 21 of 111 cas- es in which the original intention was only to provide assistance with suicide [I]. In another study, up to half the patients supplied with lethal drugs were unable to use them and required active intervention by a doctor [7]. Patients can be strongly influenced by doctors as the sole source of their information about illness, prognosis and possible interventions, so despair can easily be communicated to both the patient and family by a doctor expressing pessimism about a prognosis. On the other hand, support groups and family members are likely to impact on a patient's decision regarding euthanasia. Some doctors have reported regretting their decision to carry out euthanasia or assisted suicide [8]. Ignorance of palliative options, difficulty in diagnosing and treating depression, and failure in evaluating external pressure on patients are not uncommon, and adversely effect the decision $[6,9]$. Changing societal norms and pressures has resulted in at least one-third of patients with acquired immunodeficiency syndrome (AIDS) worldwide requesting euthanasia [10]. In Sudan, AIDS is viewed by some as a punishment by God for homosexual activity. This has resulted in some instances of AIDS patients being left to die alone without care.

\section{Conclusion}

In the present study, we sought to obviate some of the factors that have hampered previous studies by ensuring sufficient power with a large sample size, avoiding ambiguous terminology, stating clearly our definitions and using a detailed questionnaire. However, the study was to some extent skewed by the fact that the majority of Sudanese doctors live abroad. Generally, doctors within the country are very conservative and strictly opposed to euthanasia 
and assisted suicide. This being the case, there is a strong need to identify and treat depression in terminally ill patients and to provide social support to patients and their families through comprehensive programmes run by multidisciplinary teams.

\section{References}

1. Groenewoud JH et al. Clinical problems with the performance of euthanasia and physician-assisted suicide in the Netherlands. New England journal of medicine, 2000, 342(8):551-6.

2. Ganzini $L$ et al. Physicians' experiences with the Oregon Death with Dignity Act. New England journal of medicine, 2000, 342(8):557-63.

3. Conen JS et al. Attitudes toward assisted suicide and euthanasia among physicians in Washington State. New England journal of medicine, 1994, 331(2):89-94.

4. Alnashy $E$. Death after refusing treatment. Al mujtamaa, 1992, 23:57 (in Arabic).

5. Mobeireek A. The do-not-resuscitate order: indications on the current practice in Riyadh. Annals of Saudi medicine, 1995, 15(1):6-9.

6. Finlay I. Physician-assisted suicide: issues facing doctors. Hospital medicine
(London, England: 1998), 1999, 60(1):4, 6.

7. Onwuteaka-Philipsen BD et al. Active voluntary euthanasla or physiclan-assisted suicide? Journal of the American Geriatrics Society, 1997, 45(10):120813.

8. Emanuel EJ et al. The practice of euthanasia and physician-assisted suicide in the United States: adnerence to proposed safe-guards and effects on physicians. Joumal of the American Medical Association, 1990, 280:507-10.

9. Grande GE, Barclay SI, Todd CJ. Difficulty of symptom control and general practitioners' knowledge of patients' symptoms. Palliative medicine, 1997, 11(5):399-406.

10. Onwuteaka-Philipsen BD, van der Wal G. Cases of euthanasia and physicianassisted suicide among AIDS patients reported to the Public Prosecutor in North Holland. Public health, 1998. 112:53-6. 